\title{
Presumed consent in emergency neonatal research
}

D J Manning Wirral Hospital, Wirral, Merseyside

\begin{abstract}
Current methods of obtaining consent for emergency neonatal research are flawed. They risk aggravating the distress of parents of preterm and other sick neonates. This distress, and the inevitable time constraints, compromise understanding and voluntariness, essential components of adequately informed consent. Current practice may be unjust in over-representing babies of more vulnerable and deprived parents. The research findings may thus not be generalisable. Informing parents antenatally about the possible need for emergency neonatal research, with presumed consent and scope for opting out, would address these problems. It would spare parents of sick neonates, already terrified by their baby's illness, further distress. Experience with opting out suggests that recruitment might increase, thus generating earlier results, without compromising parental understanding of the nature and purpose of the research.

(Fournal of Medical Ethics 2000;26:249-253)
\end{abstract}

Keywords: consent; neonate; emergency research

\section{Introduction}

Neonatal research exposes inherent conflicts between the obligation to evaluate the efficacy and safety of new treatments, justice in recruiting subjects, and respect for autonomy in protecting subjects. Recent controversies highlight these conflicts. Conroy et al reported that $90 \%$ of drugs prescribed in a neonatal intensive care unit had not been evaluated adequately, and called for more controlled trials to remedy this. ${ }^{1}$ At the same time, an inquiry was announced following parents' claims that their newborn babies had been enrolled in a trial of continuous negative pressure ventilation for respiratory distress syndrome (RDS) without their consent. Yet the published report of this trial stated that parents consented to inclusion of their baby between two and four hours after birth. ${ }^{2}$

In this paper I outline the potential harms caused by conventional methods of seeking consent for emergency neonatal research. I argue that, in circumstances which demand this research, reasonable understanding and voluntariness are likely to be severely compromised. Thus adequately informed consent cannot be obtained. I propose an alternative approach, whereby presumed parental consent is sought antenatally, with scope for opting out. I argue that this approach, compared to conventional seeking of consent, would lessen parental distress, might increase recruitment and would acknowledge the severe impediments to autonomy experienced by parents of sick neonates.

Since research ethics committees usually require that persons asked to consent have at least 24 hours to deliberate, I define emergency research as research in circumstances when intervention must take place within 24 hours. In many relevant neonatal scenarios such as resuscitation, surfactant treatment, comparing modes of respiratory support, cerebral protection in neurologically damaged babies, and treatment of neonatal seizures, much less time is available. Research in these situations is thus subject to severe time constraints on the process of obtaining consent.

In the past 30 years, respect for autonomy has overtaken beneficence as the most important ethical consideration governing medical research. ${ }^{3}$ It is reflected in ethics codes such as the Declaration of Helsinki, which attaches great importance to obtaining consent for clinical research. When a potential research subject is competent to evaluate information about the nature and purpose of a trial, has enough time to deliberate, and is free from coercion, adequately informed consent can be obtained. Since the neonate is not autonomous, consent for trial inclusion is sought from one or both parents.

\section{Problems with current methods of seeking consent from parents of sick neonates}

A) PARENTAL DISTRESS IS EXACERBATED

The parents may be frightened by the unexpected onset and progression of preterm labour, and may have witnessed resuscitation attempts before hurried admission of their baby to the neonatal unit. In another common scenario (and a topical area of research) a full term baby has suffered hypoxic-ischaemic damage in labour, again needing resuscitation and urgent admission, and in consequence suffers respiratory failure or brain injury. In either case the parents may feel guilty and responsible for the mishap, or they may blame the hospital staff. The mother may be in pain, exhausted or experiencing the cognitive effects of analgesic or anaesthetic drugs.

Seeking consent for entry into a trial may aggravate the parents' distress. In the same breath as giving them worrying news about their baby's condition, to add further worrying information about possible risks of alternative treatments, to 
add the burden of seeking consent, and to ask them to read and sign a legalistic consent form, risks increasing their suffering. They may be further worried by the frank admission of the uncertainty that demands the research in the first place, and disappointed if their baby is randomised to control treatment. ${ }^{4}$ If these actions hurt the parents without promoting substantial understanding of the research, they are being used as means to an end, the only beneficiary being the investigator, who has been seen to follow standard procedures.

These concerns have been borne out in practice. Parents of surviving babies enrolled in the recent United Kingdom extracorporeal membrane oxygenation (ECMO) trial completed structured interviews detailing their experiences. ${ }^{6}$ Subjects were full term babies who had become very ill, often unexpectedly, in the first few hours of life. Information about their illness, and the nature and purpose of the trial comparing ECMO to conventional ventilation for respiratory failure, had to be given in these first hours. The decision whether or not to consent had to be made quickly. Parents described graphically their sense of fear and haste as they recalled being approached, sometimes disturbed from sleep, to discuss possible trial entry. Many perceived the doctor's requesting consent for trial entry as implying preference for the new treatment. They were then angry or distressed if their baby was randomised to conventional treatment. These were the recollections of parents of survivors. Those of the parents whose babies died are unlikely to be better.

B) ADEQUATE EXPLANATION OF THE TRIAL, AND OF RANDOMISATION, IS NOT POSSIBLE

Grave doubt has been cast on whether the recent delivery of a very ill baby permits reasonable parental understanding of the nature and purpose of emergency research, and autonomous authorisation for inclusion. ${ }^{7}$ Again, the experience of parents of babies in the ECMO trial bears this out. Parents reported widely differing interpretations of randomisation. Some understood it as a means for rationing access to the new treatment, and some as a solution to difficult clinical decision making. Few understood the true purpose of randomisation.

While the circumstances of recruitment to the ECMO trial might have compromised rational deliberation, similar problems were reported in trials conducted in much less fraught circumstances. Harth and Thong reported parental perceptions of, and attitudes to, consent in a trial of an anti-asthma drug. ${ }^{8}$ In this trial the children were older and clearly less sick than babies in the ECMO trial. The parents received a telephone interview and written information at least one week before the child's initial evaluation. None the less, only a minority grasped the full purpose of randomisation. While $97 \%$ of parents understood the need to determine drug efficacy, only $13 \%$ appreciated the need to determine drug safety too. Many parents underestimated possible drug risks. More than $40 \%$ of parents perceived the requirement of a signed consent form, far from protecting the research subjects, as a mechanism for protecting the investigators from litigation. The authors concluded that careful adherence to consent procedures, even in non-emergency research, did not guarantee substantial comprehension by the parents. While more could possibly be done to improve the process of communication and obtaining consent in less fraught situations and when time permits, ${ }^{9}$ it is difficult to see how substantial understanding can be improved in emergency neonatal research.

\section{C) VOLUNTARINESS IS COMPROMISED}

Parents may also suffer constraints on voluntariness, another essential component of consent. Hewlett argued that the experience of illness, the accompanying psychological responses and the vulnerability of hospitalised patients all threaten voluntariness in clinical research. ${ }^{10}$ These factors can overwhelm the parents of sick neonates. Harth and Thong suggested that psychological factors influence parents' decisions to enrol children in research, and compromise a rational decision to consent. ${ }^{11}$ They reported that parents who consented to their children entering the trial of anti-asthma treatment described above were less well-educated, had less social support, and displayed more health-seeking behaviour than those parents who refused. Silverman voiced similar concerns in reporting that clinical research in the United States has been conducted more often on impoverished minorities than on the more privileged. ${ }^{12}$ Walterspiel related how, when recruiting preterm subjects for a clinical trial, he found himself avoiding parents whom he felt were more likely to ask concerned questions. ${ }^{13}$ If these experiences are generalisable, voluntariness as well as information processing is likely to be severely compromised in research on the sick neonate.

Other ethical problems arise if there are substantial psychosocial differences between parents who consent to, and those who refuse, recruitment of their babies. Psychosocial adversity worsens the neurodevelopmental outcome for very preterm babies. If babies from deprived families are included disproportionately in trials, the outcomes may not be generalisable to the whole population. Also, justice dictates that the burden of clinical research should be borne fairly by all social groups.

Therefore, the conventional process of seeking consent poses great problems in emergency neonatal research. It may aggravate the parents' distress. This distress, and the time constraints, compromise substantial understanding and authorisation, and thus respect for autonomy. Selection bias is likely, the results may not be generalisable and on utilitarian grounds the research may therefore be unethical. Potential over-representation of the socially deprived is unjust. Can these problems be resolved?

\section{Alternative approaches - waiver of consent in adult emergency research}

Similar problems have arisen in seeking consent for emergency research in adults, for example in resusci- 
tation medicine. In particular, the subjects may be incompetent, and there may not be enough time to contact relatives. A consensus meeting of critical care researchers in 1994 concluded that circumstances arose when subject or proxy consent in emergency research could not be obtained and that patients were vulnerable, not only to research risks, but also to being deprived of potentially beneficial therapy. ${ }^{14}$

The United States Food and Drug Administration (FDA) acknowledged this dilemma, and has produced guidelines for circumstances where consent may be waived in emergency research. ${ }^{15}$ Criteria for considering a waiver include the following. The subjects must have a life-threatening illness which precludes their ability to give consent. Determination of the safety and efficacy of a new intervention is necessary. Appropriate animal and preclinical studies must support a reasonable expectation that the intervention will benefit the subjects, and that associated risks are reasonable given the severity of the illness and known risks of standard treatment. Representatives of the communities where the research will be conducted must have been consulted, and public disclosure must occur before starting the trial. The trial results must be reported publicly on completion. These latter requirements are important in emphasising the societal context of clinical research; the community has a stake, and must be consulted. They also acknowledge the case for presumed consent.

\section{Presumed consent in neonatal research}

Many of these criteria also apply to emergency neonatal research, and Morley advocated a similar approach with neonates. ${ }^{16} \mathrm{He}$ suggested some alternatives to conventional consent, including antenatal notification of a particular trial, and seeking antenatal consent from parents in the event of their baby meeting the inclusion criteria. The problem with such a specific request is that an individual baby is unlikely to meet the criteria for inclusion in a given trial. More broadly, parents could be advised during antenatal care that the hospital is engaged in neonatal research, and that this includes emergency evaluation of new treatments in, for example, very preterm babies, or those suffering perinatal brain damage. The information given could emphasise the difficulty of obtaining conventional consent in an emergency. It could be given to parents in less hurried and fraught circumstances than after delivery of a sick baby. Presumed consent could then cover several trials of emergency treatments in circumstances which precluded conventional consent. It should be supplemented by informing parents as soon as practical after birth that their baby is involved in the trial, and by regular meetings with them during their baby's involvement to share information and answer their questions - the concept of "continuing consent".

What are the criticisms of this approach? Autonomy is overridden in that consent to a specific intervention is bypassed. For the reasons outlined above, however, exercise of substantial autonomy may be impossible in emergency neona- tal research. Another concern is that prospective parents may pay little heed to trial information given antenatally, assuming that their baby is unlikely to be affected. Some may ignore it altogether, and arguably in these events presumed consent is a fiction. These problems could be minimised by careful attention to communicating the information antenatally. This is likely to be less problematic than postnatal disclosure to the few parents whose babies become sick. Antenatal disclosure might be harmful in adding to parental worry and distress. Again this could be minimised by presenting the information sensitively. In an era of high parental expectation, to acknowledge that some babies are born early or unexpectedly ill, and need emergency care, is not inappropriate. Prospective discussion of research could also be beneficial in giving parents the message that research is an essential aspect of health care, including the evaluation of new treatments.

\section{Opting out}

In contrast to conventional methods for seeking consent, in an opt out system the parents' consent would be presumed following antenatal discussion as outlined above, unless they had objected. The parents could opt out antenatally, or after inclusion of their baby in a trial, and if so the baby would receive conventional treatment. Modi argued that such a system would lessen the distress caused by seeking consent from parents of sick neonates. ${ }^{17}$ It might be kinder in that it removes at least some of the burdens of weighing the technical and emotive aspects of research, as well as the burden of having to decide whether or not to consent. Evidence supports this hypothesis. Zupancic et al reported that a significant minority of parents would prefer to have their doctor advise them on whether to include their baby in neonatal research than have to decide themselves. ${ }^{18}$

Not only might an opt out system be kinder, it might also increase recruitment, and thus generate valuable knowledge earlier. This benefit has twice been reported in low-risk, non-emergency research in children. Using an opt out system, Mutch and King reported $97 \%$ uptake for a project aimed at identifying disability, compared to $79 \%$ recruitment using the traditional opt in approach. ${ }^{19}$ Rogers et al reported similar findings in a trial of primary care follow up for disadvantaged infants. ${ }^{20}$ They also reported that mothers included via the opt out system scored significantly higher than the conventional consent group in recall and understanding of study purpose and methods. Kennedy et al reported that in Belgium a system of presumed consent for organ donation, with opting out, increased the yield of organs by $55 \%$ in 5 years. ${ }^{21}$ Fewer than $2 \%$ of the population opted out, and fewer than $10 \%$ of bereaved families objected to organ removal, compared to $20-30 \%$ in the rest of Europe. The authors speculated that one reason for the social acceptance of the system was the moral benefit of sparing grieving relatives the burden of deciding about organ donation at a time of great psychological dis- 
tress. This scenario is analogous to that of the frightened parents of a critically ill baby asked to consent to inclusion in a trial. The moral benefits of increased recruitment and sparing the parents further distress might equally apply.

Whether opting out would share the research burden more fairly is not known. Deliberation in less fraught circumstances antenatally might mitigate the psychological factors shown to influence parental participation in research, but this has not been tested in practice.

Criticisms of the opt out approach are similar to those of presumed consent, in particular that autonomy is overridden. Does the low opt out rate for organ donation outlined by Kennedy et al reflect this $?^{21}$ Do subjects fail to exercise their opt out right by default, rather than autonomously? This is a valid theoretical concern. It may be allayed by good communication of the problems and issues antenatally. The greater understanding reported for parents using the opt out approach suggests that satisfaction, rather than ignoring the opt out opportunity, was responsible for the increased recruitment reported. ${ }^{20}$ Again, regular discussion with the parents while their baby continues to be involved in the study would offset the bypassing of autonomy. It would also help restore autonomy to the parents by offering more time for information sharing, and giving them the chance to withdraw their baby from the trial.

Adequately informed parental consent should still be sought for non-therapeutic or non-urgent research in babies, for example in nutritional therapy or developmental interventions. Whether or not therapeutic and non-therapeutic research are qualitatively different, there are moral differences between emergency and non-urgent research. In the latter, the parents' autonomy is not usually constrained by the distress of delivering a critically ill baby, and there will usually be much more time to evaluate information on the nature and purpose of the study, to deliberate, and to consent or refuse. Thus, conventional methods of seeking consent, including allowing at least 24 hours for parents to deliberate, should still be used for non-urgent research.

\section{The symbolic importance of consent to trial inclusion}

Several authors have noted the paradox that a higher standard of consent is demanded for evaluation of new treatments in controlled trials than for trying such treatments unsystematically on clinical hunch. Lantos argued that, while controlled evaluation is safer than unsystematic introduction of a new treatment, the rigorous demand for consent for trial entry has symbolic significance. ${ }^{22}$ Including a patient in a trial changes the doctor-patient relationship. The patient is being used as a means to an end, and the investigator's goal extends beyond the best interests of that patient to include benefits to society. Even if this is true, the distinction from clinical practice is more apparent than real. The surgeon who publishes a case report, or outcomes and complications of an uncontrolled series of operations (such as ECMO), uses his experience with individual patients as a means to the end of advancing clinical knowledge in the same way as the researcher. The controlled trial is ethically more justifiable, however, than the uncontrolled series, as it is more likely to clarify the efficacy and safety of a new treatment, interim data analysis is more likely to identify unanticipated adverse effects, and the risks of these materialising are minimised by randomisation. There is indeed evidence of an "inclusion benefit" of partaking in controlled trials. Reported previously in adult trials, this was also seen in a placebo-controlled trial of anti-thrombin therapy in neonatal RDS. ${ }^{23}$ Babies randomised to placebo had a significantly shorter mean duration of ventilation than eligible non-randomised babies. Possible explanations include adherence to protocols reviewed rigorously by peers and ethics committees, the Hawthorne effect (the influence on performance of being observed closely), superior data analysis and interim monitoring of results. Whatever the explanations, Lantos acknowledged that the better outcomes of inclusion in a trial challenge the symbolic significance of the absolute requirement for consent. ${ }^{22}$

\section{Research and the community}

The FDA requirement that the community be consulted before consent is waived for emergency research is important in acknowledging the increasing role for society in debating dilemmas in medical ethics. It might eventually facilitate research, as lay consultation may emphasise that research, rather than clinical judgment alone, is the ethically required norm for evaluating new treatments. Rigorous peer and ethics committee review could provide adequate safeguards of the interests of subjects. Kremers et al reported early experience in community consultation in resuscitation research. ${ }^{24}$ They advertised the trial extensively in their community, and held a public meeting as part of the consultation process. The attendance was small, and all present supported the research. The authors acknowledged that further efforts might be needed to inform the public in order to elicit a broader perspective of response. None the less, their experience is encouraging and suggests that the public may support emergency research as an essential clinical responsibility. This approach could equally apply to the problem of emergency neonatal research.

\section{Summary and conclusions}

Society must acknowledge the conflicting ethical demands for research in the sick neonate. It must reconcile the competing requirements for controlled trials of new treatments, considerations of justice and respect for autonomy. Recent experience emphasises the difficulty of obtaining consent from parents of sick neonates. Current methods for obtaining this are deontologically unsound in underestimating constraints on the parents' autonomy, and in effect serving to protect the investigator. From a utilitarian 
viewpoint, they risk the harms of increasing the distress of vulnerable parents and, by selection influences, obtaining results which may not be generalisable. The burden of research may be borne disproportionately by more vulnerable and deprived families. A system of presumed consent, with opting out, for including sick neonates in appropriate trials would overcome some of these ethical problems. It would respect autonomy in acknowledging the difficulties of obtaining informed consent in emergency neonatal research. It might reduce selection bias, thus producing more generalisable conclusions, and might be more equitable. Experience with opting out in non-urgent research, and in organ donation, suggests that recruitment might increase, thus generating knowledge earlier than with conventional methods. Given current concerns about neonatal research, the lack of adequate licensing of drugs used in the neonate, and the need to evaluate emergency treatments, such as neuroprotection in asphyxiated neonates ${ }^{25}$ this debate must take place urgently.

Df Manning MD, MSc, FCPCH, DCH, DRCOG, is a Consultant Paediatrician in the Department of Paediatrics, Wirral Hospital, Wirral, Merseyside CH49 5PE.

\section{References}

1 Conroy S, McIntyre J, Choonara I. Unlicensed and off label drug use in neonates. Archives of Disease in Childhood 1999;80:F142-5.

2 Samuels MP, Raine J, Wright T, Alexander JA, Lockyer K, Spencer SA, et al. Continuous negative extrathoracic pressure in neonatal respiratory failure. Pediatrics 1996;98:1154-60.

3 Rothman DJ. Ethics and human experimentation. Henry Beecher revisited. New England fournal of Medicine 1987;317 $1195-9$

4 Perlman NB, Freedman JL, Abramovitch R, Whyte H, Kirpalani $\mathrm{H}$, Perlman $\mathrm{M}$. Informational needs of parents of sick neonates. Pediatrics $1991 ; 88: 512-8$.

5 Allmark P. Should Zelen pre-randomised consent designs be used in some neonatal trials? Fournal of Medical Ethics 1999;25 325-9.

6 Snowdon C, Garcia J, Elbourne D. Making sense of randomisation; responses of parents of critically ill babies to random allocation of treatment in a clinical trial Social Science and Medicine 1997;45:1337-55.

7 Mason S. Obtaining informed consent for neonatal ranMason S. Obtaining informed consent for neonatal ran-
domised controlled trials - an elaborate ritual? Archives of Disease in Childhood 1997;76:F143-5.
8 Harth SC, Thong YH. Parental perceptions and attitudes about informed consent in clinical research involving children. Social Science and Medicine 1995;40:1573-7.

9 van Stuijvenberg M, Suur MH, de Vos S, Tjiang GCH, Steyerberg EW, Derksen-Lubsen G, et al. Informed consent, parental awareness, and reasons for participating in a randomised controlled trial. Archives of Disease in Childhood 1998;79:120-5.

10 Hewlett S. Consent to clinical research - adequately voluntary or substantially influenced? Fournal of Medical Ethics 1996;22: $232-7$

11 Harth SC, Thong YH. Sociodemographic and motivational characteristics of parents who volunteer their children for clinical research: a controlled study. British Medical fournal 1990; 300:1372-5.

12 Silverman WA. The myth of informed consent: in daily clinical practice and in clinical trials. Fournal of Medical Ethics 1989;15: 6-11.

13 Walterspiel JN. Informed consent: influence on patient selection among critically ill premature infants. Pediatrics 1990; 85:119-21.

14 Informed consent in emergency research. Consensus statement from the Coalition Conference of Acute Resuscitation and Critical Care Researchers. Fournal of the American Medical Association 1995;273:1283-7.

15 Adams JG, Wegener J. Acting without asking: an ethical analysis of the Food and Drug Administration waiver of informed consent for emergency research. Annals of Emergency Medicine 1999;33:218-23.

16 Morley C. Consent is not always practical in emergency treatments. British Medical fournal 1997;314:1480.

17 Modi N. Clinical trials and neonatal intensive care. Archives of Disease in Childhood 1994;70:F231-2.

18 Zupancic JA, Gillie P, Streiner DL, Watts JL, Schmidt B. Determinants of parental authorization for involvement of newborn infants in clinical trials. Pediatrics 1997; 99,1:117. URL: http://www.pediatrics.org/ggi/content/full/99/1/e6

19 Mutch L, King R. Obtaining parental consent - opting in or opting out? Archives of Disease in Childhood 1985;60:979-80.

20 Rogers CG, Tyson JE, Kennedy KA, Broyles S, Hickman JF. Conventional consent with opting in versus simplified consent with opting out: an exploratory trial for studies that do not increase patient risk. fournal of Pediatrics 1998;132:606-11.

21 Kennedy I, Sells RA, Daar AS, Guttmann RD, Hoffenberg R, Lock M, et al. The case for "presumed consent" in organ donation. Lancet 1998;351:1650-2.

22 Lantos JD. The "inclusion benefit" in clinical trials. Fournal of Pediatrics 1999;134:130-1.

23 Schmidt B, Gillie P, Caco C, Roberts J, Roberts R. Do sick newborn infants benefit from participation in a randomized clinical trial? Fournal of Pediatrics 1999;134:151-5.

24 Kremers MS, Whisnant DR, Lowder L, Gregg L. Initial experience using the Food and Drug Administration guidelines for emergency research without consent. Annals of Emergency Medicine 1999;33:224-9.

25 Edwards AD, Azzopardi D. Hypothermic neural rescue treatment: from laboratory to cotside? Archives of Disease in Childhood 1998;78:F88-91.

\section{News and notes \\ The Annual Intensive Course on Medical Ethics}

The Annual Intensive Course on Medical Ethics will be held from 11 - 15 September, 2000 at the Wolfson Conference Centre, Imperial College Hammersmith Hospital Campus, London.

The course provides a stimulating multidisciplinary introduction to philosophical medical ethics for medical and nursing teachers, medical practitioners, members of ethics committees and administrators. It is organised in collaboration with the Institute of Medical Ethics. Lectures/ seminars, and small and large groups are led by leading international authorities in the field of medical ethics. PGEA and CME accreditation sought for 2000. (All previous courses have received full-range 10 session PGEA accreditation and 25 CME credits).

For further details, please contact: Bang Nong on Tel:+44 (0)20 75946882 or Hersha Mistry on Tel:+44 (0)207594 6884, Centre for Continuing Education, Imperial College, Room 526 Sherfield Building, London SW7 2AZ. Fax: +44 (0)20 7594 6883; Email: cpd@ic.ac.uk; http://www.ad.ic.ac.uk/ $\mathrm{cpd} /$ medeth.htm 